Research Article

\title{
Elevated Blood Ammonia Level Is a Potential Biological Risk Factor of Behavioral Disorders in Prisoners
}

\author{
Yunfeng Duan, ${ }^{1}$ Xiaoli Wu, ${ }^{1,2}$ Shan Liang, ${ }^{1,2}$ and Feng Jin ${ }^{1}$ \\ ${ }^{1}$ Key Laboratory of Mental Health, Institute of Psychology, Chinese Academy of Sciences, No. 16, Lincui Road, \\ Chaoyang District, Beijing 100101, China \\ ${ }^{2}$ University of Chinese Academy of Sciences, Beijing 100101, China
}

Correspondence should be addressed to Feng Jin; jinfeng@psych.ac.cn

Received 11 July 2015; Revised 1 September 2015; Accepted 6 September 2015

Academic Editor: João Quevedo

Copyright (C) 2015 Yunfeng Duan et al. This is an open access article distributed under the Creative Commons Attribution License, which permits unrestricted use, distribution, and reproduction in any medium, provided the original work is properly cited.

Hydrothion $\left(\mathrm{H}_{2} \mathrm{~S}\right)$ and ammonia $\left(\mathrm{NH}_{3}\right)$ can be toxic for the human central nervous system and cause psychological disturbances and behavioral disorders. In order to evaluate the association between the two potential toxicants and mental health, in this study, we compare a male prisoner and control population. Forty-nine male prisoners and 52 control volunteers took part in the study. An aggressive behavior assessment, the Self-Rating Depression Scale (SDS), and the State-Trait Anxiety Inventory (STAI) were used to characterize the participants' mental health status. Venous blood was collected for detection of $\mathrm{H}_{2} \mathrm{~S}_{\text {and }} \mathrm{NH}_{3}$. The results indicated that blood $\mathrm{NH}_{3}$ was significantly higher in male prisoners than in controls. However, blood $\mathrm{H}_{2} \mathrm{~S}$ was significantly lower. Blood $\mathrm{NH}_{3}$ was also significantly and positively correlated with prisoners. In the multivariate adjusted models, after controlling for age, education, marital status, and BMI, we found a positive association between $\mathrm{NH}_{3}$ and prisoners, but not blood $\mathrm{H}_{2} \mathrm{~S}$. While the functions of the two toxicants were quite different, blood $\mathrm{NH}_{3}$ may be a potential biological risk factor for behavioral disorders and blood $\mathrm{H}_{2} \mathrm{~S}$ showed neuroprotection. Additionally, the impact of other factors such as diet and gut bacteria should be considered when evaluating risk for behavioral disorders.

\section{Introduction}

Ammonia $\left(\mathrm{NH}_{3}\right)$ and hydrothion (hydrogen sulphide, $\mathrm{H}_{2} \mathrm{~S}$ ) have long been known for their poisoning effect to human central nervous system and may cause psychological disturbances and behavioral disorders. In the brain, $\mathrm{NH}_{3}$ supplied by the blood stream exerts its neurotoxic effects by inducing astrocyte swelling and triggering a reaction cascade [1-3]. Previous studies have shown that patients with shock [4] and hypoxia [5] have increased levels of blood $\mathrm{NH}_{3} . \mathrm{NH}_{3}$ is also implicated in hepatic encephalopathy, whereby its toxicity is mediated by glutamine, which is metabolized from $\mathrm{NH}_{3}$ in the brain [6]. $\mathrm{NH}_{3}$ widens junctions in the bloodbrain barrier, allowing not only pathogens, but also small molecules like glutamate along with neutrophils and water to penetrate the barrier [7]. Hyperammonemia may also result in irreversible brain damage [8]. Exposure to high level of $\mathrm{NH}_{3}$ can alter several amino acid pathways and neurotransmitter systems, cerebral energy metabolism, nitric oxide synthesis, oxidative stress, and signal transduction pathways in the brain [9].

$\mathrm{H}_{2} \mathrm{~S}$ is a neurotoxin that can cause neuronal death [10]. However, as a gasotransmitter, it is endogenously produced in the brain targets multiple molecules that affect neuronal viability in the mammalian brain [11]. In the central nervous system (CNS), it is considered to be a physiological mediator and appears to participate in cognition, memory, regulation of the cardiopulmonary functions, and neuroprotection [12]. In the peripheral nervous system, evidence suggests that $\mathrm{H}_{2} \mathrm{~S}$ may be involved in autonomic control of the cardiopulmonary and gastrointestinal functions as well as pain and inflammation [13].

One study found that the plasma level of $\mathrm{H}_{2} \mathrm{~S}$ was markedly lower in patients with depression [14]. It is also shown that $\mathrm{H}_{2} \mathrm{~S}$ synthesis in the brain is severely reduced in Alzheimer's disease (AD) patients $[15,16]$, and plasma $\mathrm{H}_{2} \mathrm{~S}$ levels are negatively correlated with the severity of $\mathrm{AD}$ [17]. Further, inhaled $\mathrm{H}_{2} \mathrm{~S}$ was able to prevent neurodegeneration 
in a mouse model of Parkinson's disease, another incurable, chronic neurodegenerative disorder [18]. All these results indicate that $\mathrm{H}_{2} \mathrm{~S}$ plays a role in neuron protection and that lower level of $\mathrm{H}_{2} \mathrm{~S}$ is harmful to normal brain function.

Additionally, $\mathrm{H}_{2} \mathrm{~S}$-related sulfur metabolites are also involved in some mental disorders. Autism spectrum disorder (ASD) is associated with a substantially reduced level of plasma sulfate but increased urinary excretion of sulphate, sulphite, and thiosulphate [19]. Parents of autism children also are subject to impairment in sulfur metabolism [20-22]. Further, ASD is also associated with excessive exposure to nitric oxide, $\mathrm{NH}_{3}$, and glutamate in the CNS [23].

It was estimated that approximately 100 million people in China and 450 million people worldwide currently suffer from mental health problems [24]. Roughly a quarter of people will experience some sort of mental disorder in their lifetime. Prisoners are prone to having mental health problems than the general population, such as depression, anxiety, violence, and even mental disorders. More than $60 \%$ of male prisoners are estimated to have serious mental problems around the world [25]. In the USA, there are ten times more prison inmates with mental problems than all the patients in state hospitals [26]. In the UK, it is estimated that about nine out of ten prisoners have mental problems while seven out of ten have at least two types of mental disorders [27]. Additionally, male prisoners are more likely to have mental problems.

There is lack of information regarding a possible association between $\mathrm{NH}_{3}$ and $\mathrm{H}_{2} \mathrm{~S}$ and mental problems in prisoners. In order to examine whether $\mathrm{NH}_{3}$ or $\mathrm{H}_{2} \mathrm{~S}$ is potential biological risk factor of mental problems, in this study, we use questionnaires and lab tests to investigate the correlation between blood $\mathrm{NH}_{3} / \mathrm{H}_{2} \mathrm{~S}$ levels and mental problems by contrasting adult male prisoners and healthy controls.

\section{Materials and Methods}

We recruited 49 male prisoners and 52 male controls from Northern China. Control participants were recruited from the area where the penitentiary is located using a systematic random sampling method. All participants were medically healthy. The jail sentences were less than one year for $82.8 \%$ of the prisoners and more than one year for the rest $17.2 \%$ $\left(M_{\text {time }}=3.38\right.$ months, SD $\left.=1.52\right)$. The crimes committed by these prisoners include both aggressive offenses (85\%) such as murder, forcible rape, robbery, and aggravated assault and nonaggressive offenses (15\%), such as burglary, national property damage, and drug-related crimes.

The SDS and STAI were used to measure depression and anxiety, respectively. In particular, aggression was evaluated using an aggressive behavior assessment (aggressivity; bullying; fighting; breaking rules; and quarrelling and the number of times in the previous one month). The assessment was rated by the correctional officers, friends, or close acquaintances, but not family members, of the participants.

To minimize the possible effects from medication, blood samples were collected only from those who were free from any drugs for at least four weeks. Blood collection was performed in the morning between 09:00 a.m. and 12:00 p.m., soon after the participants had completed the questionnaires. Venus blood was collected via venipuncture in tubes containing heparin sodium and ethylenediaminetetraacetic acid (EDTA). Whole blood $\mathrm{NH}_{3}$ levels were measured using chemical assay kits on a VITROS-350 dry chemical analyzer (Johnson \& Johnson Diagnostics, United States). Whole blood $\mathrm{H}_{2} \mathrm{~S}$ levels were determined using a Human $\mathrm{H}_{2} \mathrm{~S}$ ELISA Kit (Product number ABIN511370, Antibodies Online).

The data followed normal distributions (KolmogorovSmirnov $Z=0.92, p=0.36$ ); thus these data were used without transformation. Demographic data and psychiatric scales were used to adjust for potential confounding factors or effect modifiers.

Independent sample $t$-tests were performed to compare the mean values of continuous variables between the groups. Chi-square tests were applied to compare categorical variables between the groups. A logistic regression analysis was performed to explore the association between blood biochemical variables $\left(\mathrm{H}_{2} \mathrm{~S}\right.$ and $\mathrm{NH}_{3}$ levels $)$ and behavioral problems. In the first model, the blood biochemical variables were used as the independent variables, followed by adjustments for age, education, marital status, BMI, smoking, and drinking. In the second model, we further get psychiatric scales included for adjustment. A forward:LR (Likelihood Ratio) method was used in both models. All statistical analyses were conducted using IBM SPSS Statistics 22.0 and Microsoft Office 2007, with statistical significance defined as an alpha level of 0.05 . Two-tailed probabilities were applied throughout.

This study protocol was approved by the Institutional Ethics Committee, and a written informed consent was obtained from all participants after signing before data collection.

\section{Results and Discussion}

The demographic variables did not differ significantly between the prisoner and control groups (Table 1). Among the psychological and biological variables, depression scores, state and trait anxiety levels, and aggressive behaviors were significantly higher in male prisoners than in the controls (Table 2). The blood $\mathrm{NH}_{3}$ levels were significantly higher in the prisoners than in the controls, whereas the blood $\mathrm{H}_{2} \mathrm{~S}$ levels were significantly lower in the prisoners.

In the first model, an inverse association was found between $\mathrm{H}_{2} \mathrm{~S}$ and prisoners (OR: 0.035; 95\% CI: 0.001-1.133, $p>0.05)$, although it did not reach significance. In contrast, there was a significant positive correlation between $\mathrm{NH}_{3}$ and prisoners (OR: 1.111; 95\% CI: 1.055-1.171, $p<0.001$ ). A positive association between $\mathrm{NH}_{3}$ and prisoners (OR: 1.189; 95\% CI: $1.072-1.319, p<0.001$ ) was found even in the multivariate adjusted model, which controlled for potential confounders (age, education, marital status, and BMI). In the second model, after controlling for potential confounders (age, education, marital status, BMI, SDS, STAI-S, and STAI$\mathrm{T}$ ), we only found a significant positive correlation between 
TABLE 1: Demographic summary of the participants.

\begin{tabular}{lcccc}
\hline & $\begin{array}{c}\text { Prisoner } \\
(n=49)\end{array}$ & $\begin{array}{c}\text { Control } \\
(n=52)\end{array}$ & $t / \chi^{2}$ & $p$ value \\
\hline Age & $33.20(1.27)$ & $30.13(1.15)$ & 1.8 & 0.080 \\
Marital status & & & & \\
$\quad$ Single & $67.40 \%$ & $51.10 \%$ & $1.58^{*}$ & 0.053 \\
$\quad$ Married & $25.60 \%$ & $46.70 \%$ & & \\
$\quad$ Others & $7 \%$ & $12.80 \%$ & & \\
Education & & & & \\
$\quad$ Primary school & $45 \%$ & $30.50 \%$ & $-1.79^{*}$ & 0.056 \\
$\quad$ High school & $45.50 \%$ & $57.70 \%$ & & \\
$\quad$ Higher & $9.10 \%$ & $12.80 \%$ & & \\
BMI & $22.90(2.8)$ & $24.20(3.80)$ & -1.87 & 0.060 \\
Smokers & $75 \%$ & $57.80 \%$ & $2.95^{*}$ & 0.086 \\
Drinkers & $54.40 \%$ & $46.70 \%$ & $0.55^{*}$ & 0.457 \\
\hline
\end{tabular}

${ }^{*}$ Chi-square test result.

TABLE 2: Independent $t$-test for psychological and biological test results.

\begin{tabular}{|c|c|c|c|c|}
\hline & $\begin{array}{c}\text { Prisoners } \\
N=49 \\
\text { Mean (SD) }\end{array}$ & $\begin{array}{c}\text { Controls } \\
N=52 \\
\text { Mean (SD) }\end{array}$ & $t$ & $p$ value \\
\hline STAI-S & $2.4(0.5)$ & $1.9(0.4)$ & 4.61 & 0.000 \\
\hline STAI-T & $2.5(0.4)$ & $2.0(0.4)$ & 2.54 & 0.013 \\
\hline SDS & $42.5(7.5)$ & $37.4(9.0)$ & 2.85 & 0.006 \\
\hline Aggression & $10.5(2.6)$ & $7.8(1.1)$ & 6.58 & 0.000 \\
\hline $\mathrm{H}_{2} \mathrm{~S}(\mathrm{pg} / \mathrm{mL})$ & $0.4(0.2)$ & $0.5(0.15)$ & -2.36 & 0.021 \\
\hline $\mathrm{NH}_{3}(\mu \mathrm{mol} / \mathrm{L})$ & $42.2(10.1)$ & $30.2(13.8)$ & 4.70 & 0.000 \\
\hline
\end{tabular}

$\mathrm{NH}_{3}$ and prisoners (OR: 0.730; 95\% CI: 0.576-0.924, $p<$ 0.01 ). It can thus be concluded that blood $\mathrm{NH}_{3}$, but not blood $\mathrm{H}_{2} \mathrm{~S}$, successfully predicted each participant's group.

From the study, blood $\mathrm{NH}_{3}$, but not $\mathrm{H}_{2} \mathrm{~S}$, was an independent prognostic factor for behavioral disorder, and thus these biomarkers may be useful in predicting poor mental status for screening or intervention purposes.

Elevated $\mathrm{NH}_{3}$ is often detected in intrinsic liver disease but can also be caused by abnormal catabolic state (e.g., excess of amino acids degradation) or reduced clearance [28]. Since all the participants claimed to be healthy and should not have liver disease, the elevated $\mathrm{NH}_{3}$ should instead result from food digestion, reduced clearance, or both.

Mounting evidence has shown that diet can influence our feelings of anxiety [24], depression [29-31], anger [32], and stress [33] and even lead to psychological conditions such as attention deficit hyperactivity disorder [34]. In particular, metabolism of protein and amino acids, the primary nutritional intakes from diets, is important to the maintenance of mental health because proteins are degraded to amino acids and then to $\mathrm{H}_{2} \mathrm{~S}$ and $\mathrm{NH}_{3}$. Meat is a valuable source of protein and fat, which are beneficial to health in appropriate amounts but harmful in excess. It is suggested that eating meat as part of an unhealthy diet can lead to mental illness and psychological distress [35-37]. One recent study reported that stress levels were inversely related to meat consumption after adjusting for sex, age, smoking, and physical activity [33]. Additionally, studies in adults have shown that diets high in processed foods, like chocolate, refined grains, and processed meat, may increase the likelihood of depression and both trait and state anxiety levels were significantly related to the consumption of processed foods [38]. Another study found that males were more likely to have diets high in animal products and that unhealthy eating patterns (including meat and snack foods) were associated with higher risk for behavioral disorders like depression and anxiety [39].

However, lowering meat consumption does not necessarily reduce $\mathrm{NH}_{3}$ production, but the dietary fiber (high in fruits and vegetables) does [40].

Some studies have reported that women who consumed less than the recommended amount of red meat were more likely to be diagnosed with a depressive or anxiety disorder than those who consumed the recommended amount [41]. Another study showed that lower levels of stress were linked to a diet high in unsaturated oils, grains, fruits, vegetables, meat, and dairy products [33]. Therefore, diets containing fruits, vegetables, and nuts are considered an important protective factor against psychological illness, promoting or maintaining a healthy mental state [30, 42-44].

Although many studies have indicated a relationship between diet and mental health, the biological mechanisms involved are still not well understood. It is suggested that $\mathrm{NH}_{3}$ and $\mathrm{H}_{2} \mathrm{~S}$ both were affected by the gut microbiota. Certain bacteria species residing the mouth and gastrointestinal tract can generate $\mathrm{H}_{2} \mathrm{~S}$ during the metabolism of sulfhydrylcontaining amino acids (e.g., cysteine) from diet [45]. The Desulfovibrio species in the gut can also metabolize sulfate to $\mathrm{H}_{2} \mathrm{~S}$ [46]. Excessive $\mathrm{NH}_{3}$ produced by yeast in the gut has also been linked to chronic inflammation and autism $[47,48]$.

In this study, we used an exclusively male population; a report showed that men typically consume more processed foods and meat but less vegetables than do women [38, 49]. Depressive mood and aggression are also related to amino acid metabolism, and dietary tryptophan depletion has been shown to increase aggression in healthy men, likely by decreasing brain serotonin $[50,51]$. The increased $\mathrm{NH}_{3}$ might be caused by diet and we hypothesized that an unhealthy diet would be associated with a higher likelihood of depressive and anxiety disorders and a greater prevalence of psychological symptoms.

\section{Conclusions}

In sum, blood $\mathrm{NH}_{3}$ could act as a potential biological marker of behavioral disorders. However, further studies are needed to address how blood $\mathrm{NH}_{3}$ regulates brain function and contributes to the development of behavioral disorders. In particular, it should be taken into consideration whether the high blood $\mathrm{NH}_{3}$ levels result from increased production or decreased clearance, as well as the liver health status of participants. Additionally, production of $\mathrm{NH}_{3}$ and $\mathrm{H}_{2} \mathrm{~S}$ from endogenous or exogenous sources, that is, host or gut 
microbiota, should be distinguished. Moreover, since $\mathrm{NH}_{3}$ and $\mathrm{H}_{2} \mathrm{~S}$ carry distinct functions, the impact from factors such as diet and gut bacteria should also be considered to explore the relationship between $\mathrm{H}_{2} \mathrm{~S}$ and behavioral disorders.

\section{Disclaimer}

The funders played no role in the design or conduct of the study, collection, management, analysis, and interpretation of the data or in preparation, review, or approval of the paper.

\section{Conflict of Interests}

The authors declare no competing interests.

\section{Authors' Contribution}

Yunfeng Duan and Xiaoli Wu contributed equally to this work. Yunfeng Duan and Feng Jin conceived and designed the experiments. Yunfeng Duan and Xiaoli Wu performed the experiments and wrote the paper. Shan Liang contributed reagents/materials/analysis tools.

\section{Acknowledgments}

This study was supported by the Key Laboratory of Mental Health, Institute of Psychology, Chinese Academy of Sciences and China Postdoctoral Science Foundation (Authorization no. 2013M541072). The authors thank all of the subjects who participated in this study and Liuqi Gu at Cornell University for helpful comments and suggestions.

\section{References}

[1] A. Watanabe, M. Fujiwara, S. Tominaga, and H. Nagashima, "Elevation of ammonia contents in the cerebral hemisphere under the blood-brain barrier opening," Hiroshima Journal of Medical Sciences, vol. 36, no. 4, pp. 415-416, 1987.

[2] A. J. L. Cooper and F. Plum, "Biochemistry and physiology of brain ammonia," Physiological Reviews, vol. 67, no. 2, pp. 440519, 1987.

[3] M. D. Norenberg, A. R. Jayakumar, K. V. Rama Rao, and K. S. Panickar, "New concepts in the mechanism of ammoniainduced astrocyte swelling," Metabolic Brain Disease, vol. 22, no. 3-4, pp. 219-234, 2007.

[4] M. Kekomäki and I. Louhimo, "Blood ammonium concentration during hemorrhagic shock in the rabbit," Acta Chirurgica Scandinavica, vol. 137, no. 8, pp. 745-748, 1971.

[5] Y. Sakaguchi, K. Yuge, M. Yoshino, F. Yamashita, and T. Hashimoto, "Hyperammonemia in the neonate with hypoxia," in Urea Cycle Diseases, pp. 147-152, Springer, 1982.

[6] J. Albrecht, M. Zielińska, and M. D. Norenberg, "Glutamine as a mediator of ammonia neurotoxicity: a critical appraisal," Biochemical Pharmacology, vol. 80, no. 9, pp. 1303-1308, 2010.

[7] M. Skowrońska and J. Albrecht, "Alterations of blood brain barrier function in hyperammonemia: an overview," Neurotoxicity Research, vol. 21, no. 2, pp. 236-244, 2012.
[8] J. Häberle, "Clinical and biochemical aspects of primary and secondary hyperammonemic disorders," Archives of Biochemistry and Biophysics, vol. 536, no. 2, pp. 101-108, 2013.

[9] O. Braissant, V. A. McLin, and C. Cudalbu, "Ammonia toxicity to the brain," Journal of Inherited Metabolic Disease, vol. 36, no. 4, pp. 595-612, 2013.

[10] Y. Kurokawa, F. Sekiguchi, S. Kubo et al., "Involvement of ERK in NMDA receptor-independent cortical neurotoxicity of hydrogen sulfide," Biochemical and Biophysical Research Communications, vol. 414, no. 4, pp. 727-732, 2011.

[11] H. Kimura, "Hydrogen sulfide: Its production, release and functions," Amino Acids, vol. 41, no. 1, pp. 113-121, 2011.

[12] H. Kimura, "Physiological role of hydrogen sulfide and polysulfide in the central nervous system," Neurochemistry International, vol. 63, no. 5, pp. 492-497, 2013.

[13] W. Rong, H. Kimura, and D. Grundy, "The neurophysiology of hydrogen sulfide," Inflammation and Allergy-Drug Targets, vol. 10, no. 2, pp. 109-117, 2010.

[14] S. M. Cheng, J. F. Chen, and Z. R. Li, "Role of plasma carbon monoxide and hydrogen sulfide in depression," Life Science Research, vol. 18, pp. 407-410, 2014.

[15] P. Kamoun, "Endogenous production of hydrogen sulfide in mammals," Amino Acids, vol. 26, no. 3, pp. 243-254, 2004.

[16] K. Eto, T. Asada, K. Arima, T. Makifuchi, and H. Kimura, "Brain hydrogen sulfide is severely decreased in Alzheimer's disease," Biochemical and Biophysical Research Communications, vol. 293, no. 5, pp. 1485-1488, 2002.

[17] X. Q. Liu, X. Q. Liu, P. Jiang, H. Huang, and Y. Yan, "Plasma levels of endogenous hydrogen sulphide and homocysteine in patients with Alzheimer's disease and vascular dementia and the significance theoreof," Zhonghua Yi Xue Za Zhi, vol. 88, pp. 2246-2249, 2008.

[18] K. Kida, M. Yamada, K. Tokuda et al., "Inhaled hydrogen sulfide prevents neurodegeneration and movement disorder in a mouse model of Parkinson's disease," Antioxidants and Redox Signaling, vol. 15, no. 2, pp. 343-352, 2011.

[19] R. H. Waring and L. V. Klovrza, "Sulphur metabolism in autism," Journal of Nutritional and Environmental Medicine, vol. 10, no. 1, pp. 25-32, 2000.

[20] D. A. Geier, J. K. Kern, C. R. Garver et al., "Biomarkers of environmental toxicity and susceptibility in autism," Journal of the Neurological Sciences, vol. 280, no. 1-2, pp. 101-108, 2009.

[21] S. Jill James, S. Melnyk, S. Jernigan, A. Hubanks, S. Rose, and D. W. Gaylor, "Abnormal transmethylation/transsulfuration metabolism and DNA hypomethylation among parents of children with autism," Journal of Autism and Developmental Disorders, vol. 38, no. 10, pp. 1966-1975, 2008.

[22] S. J. James, P. Cutler, S. Melnyk et al., "Metabolic biomarkers of increased oxidative stress and impaired methylation capacity in children with autism," The American Journal of Clinical Nutrition, vol. 80, no. 6, pp. 1611-1617, 2004.

[23] S. Seneff, A. Lauritzen, R. M. Davidson, and L. Lentz-Marino, "Is encephalopathy a mechanism to renew sulfate in autism?" Entropy, vol. 15, no. 1, pp. 372-406, 2013.

[24] L. Christensen and L. Pettijohn, "Mood and carbohydrate cravings," Appetite, vol. 36, no. 2, pp. 137-145, 2001.

[25] A. J. Wakefield, J. M. Puleston, S. M. Montgomery, A. Anthony, J. J. O'Leary, and S. H. Murch, "The concept of enterocolonic encephalopathy, autism and opioid receptor ligands," Alimentary Pharmacology \& Therapeutics, vol. 16, no. 4, pp. 663674, 2002. 
[26] TAC, The Treatment of Persons with Mental Illness in Prisons and Jails: A State Survey (Abridged), Treatment Advocacy Center, 2014, http://www.tacreports.org/storage/documents/ treatment-behind-bars/treatment-behind-bars-abridged.pdf.

[27] N. Singleton, H. Meltzer, and R. Gatward, Psychiatric Morbidity among Prisoners in England and Wales, Office for National Statistics, Stationery Office, London, UK, 1998.

[28] S. Kumar and S. K. Asrani, "Non-cirrhotic hyperammonemiawhen high ammonia is not always from cirrhosis," Current Hepatology Reports, vol. 14, no. 1, pp. 25-31, 2015.

[29] K. M. Appleton, T. J. Peters, R. C. Hayward et al., "Depressed mood and n-3 polyunsaturated fatty acid intake from fish: non-linear or confounded association?" Social Psychiatry and Psychiatric Epidemiology, vol. 42, no. 2, pp. 100-104, 2007.

[30] C. Sanhueza, L. Ryan, and D. R. Foxcroft, "Diet and the risk of unipolar depression in adults: systematic review of cohort studies," Journal of Human Nutrition and Dietetics, vol. 26, no. 1, pp. 56-70, 2013.

[31] T. N. Akbaraly, E. J. Brunner, J. E. Ferrie, M. G. Marmot, M. Kivimaki, and A. Singh-Manoux, "Dietary pattern and depressive symptoms in middle age," The British Journal of Psychiatry, vol. 195, no. 5, pp. 408-413, 2009.

[32] J. B. Deijen, M. L. Heemstra, and J. F. Orlebeke, "Dietary effects on mood and performance," Journal of Psychiatric Research, vol. 23, no. 3-4, pp. 275-283, 1989.

[33] H. Roohafza, N. Sarrafzadegan, M. Sadeghi, M. RafieianKopaei, F. Sajjadi, and H. Khosravi-Boroujeni, "The association between stress levels and food consumption among Iranian population," Archives of Iranian Medicine, vol. 16, no. 3, pp. 145$148,2013$.

[34] A. L. Howard, M. Robinson, G. J. Smith, G. L. Ambrosini, J. P. Piek, and W. H. Oddy, "ADHD is associated with a 'Western' dietary pattern in adolescents," Journal of Attention Disorders, vol. 15, no. 5, pp. 403-411, 2011.

[35] F. N. Jacka, P. J. Kremer, E. R. Leslie et al., "Associations between diet quality and depressed mood in adolescents: results from the Australian Healthy Neighbourhoods Study," Australian and New Zealand Journal of Psychiatry, vol. 44, no. 5, pp. 435-442, 2010.

[36] F. N. Jacka, J. A. Pasco, A. Mykletun et al., "Association of western and traditional diets with depression and anxiety in women," American Journal of Psychiatry, vol. 167, no. 3, pp. 305311, 2010.

[37] M. Robinson, G. E. Kendall, P. Jacoby et al., "Lifestyle and demographic correlates of poor mental health in early adolescence," Journal of Paediatrics and Child Health, vol. 47, no. 1-2, pp. 5461, 2011.

[38] M. Bakhtiyari, E. Ehrampoush, N. Enayati et al., "Anxiety as a consequence of modern dietary pattern in adults in TehranIran," Eating Behaviors, vol. 14, no. 2, pp. 107-112, 2013.

[39] T.-T. Wenga, J.-H. Haoa, Q.-W. Qiana et al., "Is there any relationship between dietary patterns and depression and anxiety in Chinese adolescents?" Public Health Nutrition, vol. 15, no. 4, pp. 673-682, 2012.

[40] F. Philippe, M. Laitat, J. Wavreille, B. Nicks, and J. Cabaraux, "Effects of a high-fibre diet on ammonia and greenhouse gas emissions from gestating sows and fattening pigs," Atmospheric Environment, vol. 109, pp. 197-204, 2015.

[41] F. N. Jacka, J. A. Pasco, L. J. Williams et al., "Red meat consumption and mood and anxiety disorders," Psychotherapy and Psychosomatics, vol. 81, no. 3, pp. 196-198, 2012.
[42] A. Sánchez-Villegas, P. Henríquez, M. Bes-Rastrollo, and J. Doreste, "Mediterranean diet and depression," Public Health Nutrition, vol. 9, no. 8, pp. 1104-1109, 2006.

[43] A. Nanri, Y. Kimura, Y. Matsushita et al., "Dietary patterns and depressive symptoms among Japanese men and women," European Journal of Clinical Nutrition, vol. 64, no. 8, pp. 832839, 2010.

[44] A. Sánchez-Villegas, M. Delgado-Rodríguez, A. Alonso et al., "Association of the mediterranean dietary pattern with the incidence of depression: the seguimiento universidad de navarra/university of navarra follow-up (sun) cohort," Archives of General Psychiatry, vol. 66, no. 10, pp. 1090-1098, 2009.

[45] M. M. Gadalla and S. H. Snyder, "Hydrogen sulfide as a gasotransmitter," Journal of Neurochemistry, vol. 113, no. 1, pp. 14-26, 2010.

[46] S. M. Finegold, J. Downes, and P. H. Summanen, "Microbiology of regressive autism," Anaerobe, vol. 18, no. 2, pp. 260-262, 2012.

[47] Z. Palková and L. Váchová, "Ammonia signaling in yeast colony formation," in International Review of Cytology, W. J. Kwang, Ed., pp. 229-272, Academic Press, 2003.

[48] C. J. Burrus, "A biochemical rationale for the interaction between gastrointestinal yeast and autism," Medical Hypotheses, vol. 79, no. 6, pp. 784-785, 2012.

[49] C. L. Larsson, K. S. Klock, A. Nordrehaug Åstrom, O. Haugejorden, and G. Johansson, "Lifestyle-related characteristics of young low-meat consumers and omnivores in Sweden and Norway," Journal of Adolescent Health, vol. 31, no. 2, pp. 190-198, 2002.

[50] F. G. Moeller, D. M. Dougherty, A. C. Swann, D. Collins, C. M. Davis, and D. R. Cherek, "Tryptophan depletion and aggressive responding in healthy males," Psychopharmacology, vol. 126, no. 2, pp. 97-103, 1996.

[51] A. J. Cleare and A. J. Bond, “The effect of tryptophan depletion and enhancement on subjective and behavioural aggression in normal male subjects," Psychopharmacology, vol. 118, no. 1, pp. 72-81, 1995. 


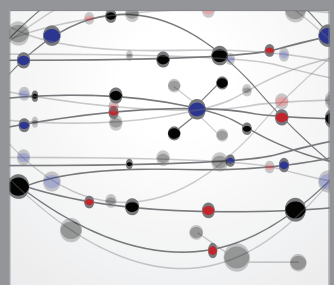

The Scientific World Journal
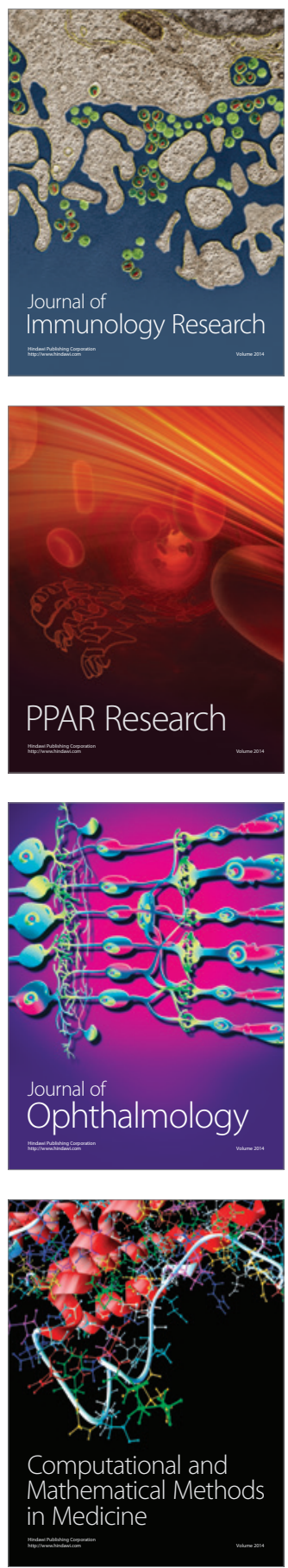

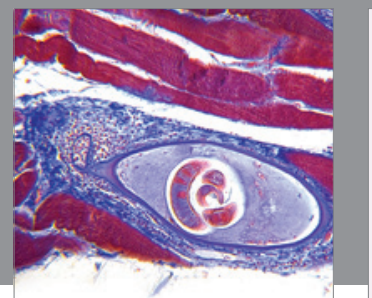

Gastroenterology

Research and Practice
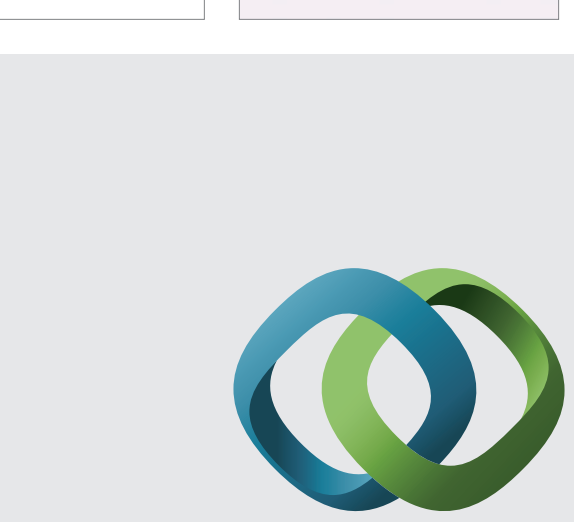

\section{Hindawi}

Submit your manuscripts at

http://www.hindawi.com
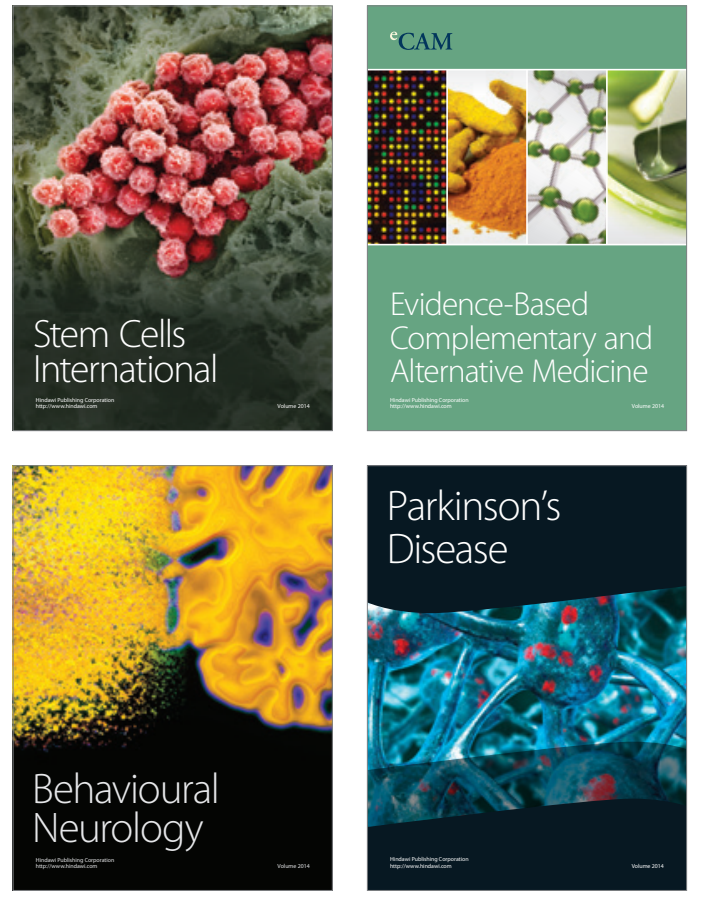
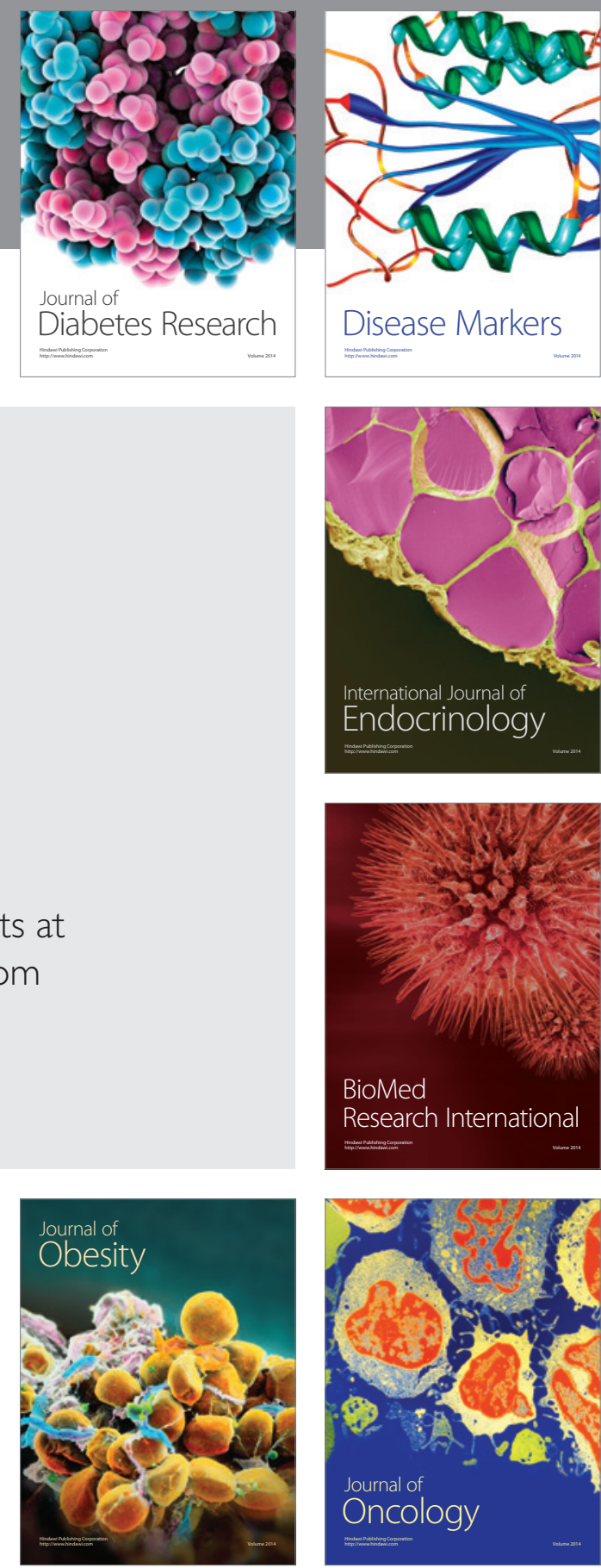

Disease Markers
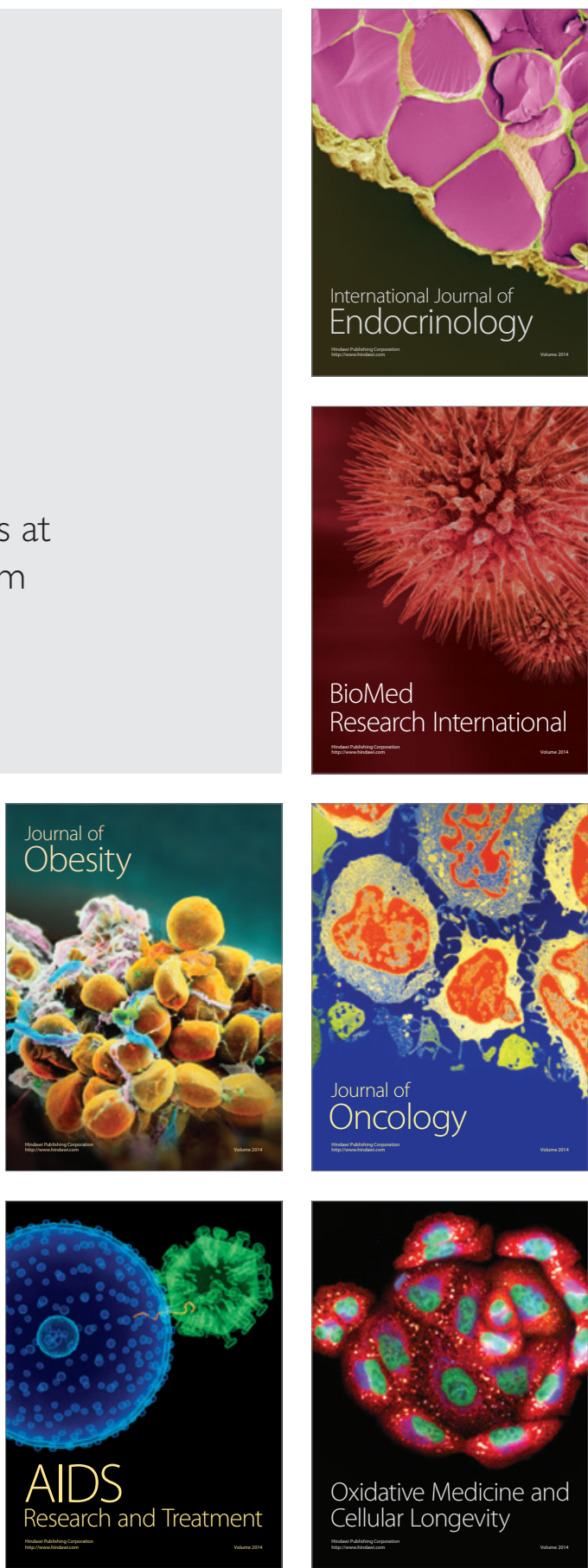